\title{
Inclusão Escolar versus o peso do diagnóstico no entendimento das diferenças
}

\section{School Inclusion versus the weight of diagnosis in understanding of differences}

\section{Inclusión escolar versus el peso del diagnóstico en la comprensión de las diferencias}

\author{
Maria Almerinda de Souza Matos \\ Natália dos Santos Chaves \\ Universidade Federal do Amazonas (Brasil)
}

ORRÚ, Silvia Ester. O re-inventar da inclusão: os desafios da diferença no processo de ensinar e aprender. Petrópolis: Vozes, 2017.

A Professora Silvia Ester Orrú é docente da faculdade de Educação da Universidade de Brasília, atua como professora colaboradora na Universidade Federal de Afenas, no Programa de Pós-graduação em Educação e coordena - Laboratório de Estudos e Pesquisas em Aprendizagem e Inclusão (LEPAl/ CNPq). Em suas publicações científicas, encontramos textos relacionados com a temática da Educação em um contexto inclusivo.

O livro "O re-inventar da inclusão: os desafios da diferença no processo de ensinar e aprender" fundamenta-se teoricamente em autores que integram a corrente filosófica francesa contemporânea, no pensamento pós-moderno e pós-estruturalista. O livro convida os educadores e leitores a fazerem uma revisão crítica sobre a complexidade da inclusão e sobre o modo como pensamos e fazemos a Educação. Defende a necessidade de uma virada teórico-metodológica para que possamos entender de fato o que é e como é incluir, problematizando o peso do diagnóstico médico no entendimento da diferença, seja na escola, ou em outros ambientes formadores. Isso leva o leitor a refletir sobre as diferenças e seus reflexos na sociedade.

O livro está organizado em onze capítulos: 1 - $\bigcirc$ universal e o singular; 2 - $O$ diagnóstico universal e a diferença singular; 3 - A busca da semelhança, da diferença e da cura pelo diagnóstico; 4- As políticas e os problemas -O trato das probidades no seio da escola; 5 - A inclusão menor -pelo microscópio se vê maior entre linhas e fronteiras; 6 - Entre linhas e fronteiras; 7 - A 
natureza hibris do ser humano, da Educação, da inclusão e a aprendizagem; 8 - Inclusão é coisa de supervivente; 9 - Vozes sem eco: a mãe, a diretora da escola, a professora, as vozes das crianças, a mulher com esclerose múltipla, a moça com Síndrome de Down, a refugiada da Síria, o ex-presidiário, o juiz; 10 -A solidão do excluído em todo o tempo é povoada; 11 - Inclusão na diferença: incompletudes.

No primeiro capítulo, critica os vetores que servem como instrumento de poder para universalizar, domesticar, controlar, dominar e segregar o outro na tentativa de normalizar a vida desde os primórdios do século XVII. Isso, com a apresentação de um posicionamento resistente e contrário à lógica do mercado, do produtivismo, do lucro e da manipulação do indivíduo. A leitura desse capítulo é fundamental para a compreensão de conceitos e expressões utilizadas pela autora ao longo da obra, pois aborda uma discussão sob a égide da filosofia da diferença. Fundamenta-se teoricamente nos estudos de Foucault, sobre o poder disciplinar e sua constituição em vetores a partir das políticas de caráter macro e micromolecular, e no conceito de agenciamento de Deleuze.

No segundo e no terceiro capítulos analisa os diagnósticos biomédi2 cos presentes no DSM e no CID (o paradigma universal). Os classifica como mecanismos produtores de exclusão que agrupam as pessoas por patologias, vetores catalizadores da segregação, da classificação, da coisificação do outro, ignorando a presença de componentes históricos e sociais que constituem o ser como singular. Enfatiza a expropriação da escola de sua função social de educar, delegando à medicina o poder de dizer quem pode e quem não pode aprender. Assim, a escola se expropria da Educação para encontrar legitimidade para a segregação e seus mecanismos de exclusão. Fundamentada na obra "Repetição e diferença" de Deleuze, faz um paralelo com o filme X-Men e chama a atenção do leitor para a importância de olhar para a singularidade, a subjetividade e para a multiplicidade que nos constitui como sujeitos únicos.

No quarto e quinto capítulos, aborda leis e documentos que norteiam a Educação no Brasil, principalmente sobre aqueles que tratam do direito de todos à Educação. Afirma que o termo "preferencialmente", constante nos documentos, abre uma brecha para que mecanismos de exclusão ditem as normas para o ensino. Faz uma crítica aos métodos de ensino pedagógicos e às suas práticas homogeneizadoras que desconsideram a capacidade que 
cada pessoa tem de aprender em seu próprio ritmo, de acordo com suas singularidades.

Defende, no sexto capítulo, que inclusão é fazer COM, fazer JUNTO e não isolado, segregado. Afirma que a inclusão deve ser problematizada, debatida, para que ninguém seja deixado de fora, que aconteça para além da força da lei, todos os dias, nos mais diversos e minúsculos espaços de aprendizagem. Isso, pela convicção de que seus pressupostos são como uma organização de crenças, uma filosofia de vida. Reverbera a inclusão que acontece na fronteira na linha divisória incluídos/excluídos, que não serve ao interesse do Estado, do capital, mas que materializa o grito dos excluídos, assumindo um papel de agente transformador da sociedade, ameaçando a ordem pré-determinada nas instituições de ensino que moldam o humano. A inclusão não incita a divisão de turmas por classes organizadas a partir da psicometria em um espaço à parte, criado somente para os excluídos.

No sétimo e oitavo capítulos, chama a atenção para o caráter híbrido, misto e diversificado da natureza humana, da educação, da inclusão e da aprendizagem. Afirma que a inclusão é para pessoas que são resistentes, resilientes e, sobretudo, para quem sobrevive um ao outro, configurando-se em uma experiência de vida.

O ponto alto do livro centra-se nas entrevistas realizadas com os "superviventes à inclusão" para ouvir deles o que é a diferença para cada um dos entrevistados e, assim, melhor compreender como eles se fortalecem a partir das próprias dificuldades, superadas ou não. Os capítulos seguintes, que concluem o livro, são pautados em reflexões sobre a inclusão e as diferenças a partir do essencial na fala dos entrevistados. Ressaltamos que a autora não realizou uma análise das falas dos entrevistados, houve um diálogo, uma escuta, um compartilhamento de saberes e vivências.

Podemos concluir que o norte do livro se dá na complexidade da inclusão e da diferença, o que induz a pensar que a diferença é um atributo de todo ser humano, que faz parte condição humana ser diferente, e que é preciso olhar para singularidade existente dentro de cada aluno. Isso nos leva a pensar sobre a forma como fazemos Educação, que não podem existir turmas homogêneas, que precisamos romper com o atual modelo de ensino, com metodologias e currículos inflexíveis. Nos alerta para a importância de rompermos com os padrões homogeneizadores impostos pelo diagnóstico biomédico, 
pois esta é uma igualdade universal. $\bigcirc$ texto é escrito em uma linguagem clara e acessível, fundamentado filosoficamente em pensadores como Foucault e Deleuze. É uma leitura indicada para estudantes e, principalmente, para profissionais da área da Educação, porém é recomendável para todos que, direta ou indiretamente, atuam em qualquer espaço formativo e educativo.

Profa Dra. Maria Almerinda de Souza Matos Doutora em Educação Universidade Federal do Amazonas (Brasil) Departamento de Teorias e Fundamentos-DTF Líder do Núcleo de Estudos e Pesquisas em psicopedagogia Diferencial - NEPPD Orcid id: https:/ / orcid.org/0000-0002-4776-2 155 E-mail: profalmerinda@hotmail.com Universidade Federal do Amazonas (Brasil) Programa de Pós-graduação em Educação- PPGE/ UFAM Professora e Pedagoga na Secretaria Municipal de Educação-SEMED Pesquisadora no Núcleo de Estudos e Pesquisas em Psicopedagogia Diferencial- NEPPD Orcid id: https:/ / orcid.org/0000-0003-1758-042X E-mail: nataliaschaves@gmail.com

Recebida 21 jun. 2020 Aceita 9 jul. 2020 